\title{
Propuesta didáctica para abordar la traducción técnica: trabajo colaborativo y Aprendizaje Basado en Proyectos
}

\author{
Didactic Approach to Technical Translation: Collaborative Work and Project Based Learning \\ Proposta didática para abordar a tradução técnica: trabalho colaborativo e aprendizagem \\ baseada em projetos
}

Romina Valeria Carabajal* (https://orcid.org/0000-0001-5294-1134)

Departamento de Traductorado- Centro de Estudios en Traducción “Bernabé Duggan” (CET), Facultad de Lenguas, Universidad Nacional del Comahue (Sede General Roca), Río Negro, Argentina
Recibido: 28-09-17

Revisado: $30-10-17$

Aceptado: $22-11-17$

Publicado: $18-12-17$
RESUMEN. Dentro del ámbito de la didáctica de la traducción la implementación de metodologías que integren teoría y práctica es un gran desafío. La necesidad de modificar la enseñanza de la traducción especializada no es ajena a nuestra práctica docente en la materia Traducción Técnica del Traductorado Público en idioma inglés, Facultad de Lenguas, Universidad Nacional del Comahue (Argentina), donde la propuesta metodológica que se presenta en la traducción de textos técnicos integra diferentes propuestas didácticas para modificar la metodología de enseñanza de la traducción especializada. El objetivo del presente trabajo es describir las actividades en el marco del trabajo colaborativo, basado en proyectos que realizan los estudiantes de Traducción Técnica, para construir su propio aprendizaje de manera autónoma, y el rol docente como guía del proceso. Al implementar esta nueva metodología se espera que los futuros traductores adquieran las herramientas necesarias para desarrollarse de manera eficiente en el mercado laboral.
Palabras clave:

Didáctica de

la Traducción,

Traducción

Técnica,

Enfoque

por tareas,

Enfoque

ABSTRACT. The design of new methodological perspectives that combine different translation theories with the practice of translation is a difficult task in the area of

Keywords: translation didactics,

Citar como: Carabajal, R. V. (2017). Propuesta didáctica para abordar la Traducción Técnica: trabajo colaborativo y aprendizaje basado en proyectos. Revista Digital de Investigación en Docencia Universitaria, 11(2), 192-202. doi: http://dx.doi.org/10.19083/ridu.11.571

*E-mail: romina.carabajaldafadel.uncoma.edu.ar 
translation didactics. The need to include changes in the teaching of specialized translation represents a challenge for teachers of Technical Translation of the English Public Translation graduate program at the School of Languages of Universidad Nacional del Comahue (Argentina). The methodological perspective applied to the translation of technical texts brings together different didactic strategies so as to modify the traditional

technical translation task-based approach, constructivist approach methodology. This work aims at describing activities, focused on collaborative work and project-based learning, that students of Technical Translation carry out in order to foster autonomy in their own learning process with the teacher's role as a facilitator of the process. It is believed that the application of this new methodology will provide students with the necessary abilities to perform their job appropriately in the labor market.

RESUMO. No campo da didática da tradução a implementação de metodologias que integrem teoria e prática a presenta um grande desafio. A necessidade de modificar o ensino da tradução especializada não está distante da nossa prática docente na disciplina de Tradução Técnica do Tradutorado Público em Inglês, Faculdade de Idiomas, Universidade Nacional de Comahue (Argentina), onde a proposta metodológica apresentada na tradução de textos técnicos integra diferentes propostas didáticas para modificar a metodologia do ensino de tradução especializada. O objetivo deste trabalho é descrever as atividades no âmbito do trabalho colaborativo e com base em projetos realizados por estudantes de Tradução Técnica para construir sua própria aprendizagem de forma autônoma e o papel

Palavraschave:

Didática de Tradução,

Tradução

Técnica,

Enfoque

por Tarefas,

Abordagem Sócioconstrutivista do professor como guia do processo. Ao implementar esta nova metodologia, se espera que os futuros tradutores adquiram as ferramentas necessárias para se desenvolver de forma eficiente no mercado de trabalho.

En el proceso de enseñanza aprendizaje de la traducción especializada se debe considerar la integración de conceptos teóricos en la práctica de traducción a la realidad profesional. Para ello es necesario implementar una metodología de trabajo que contemple estos aspectos. La necesidad de incluir estos cambios en el ámbito de la enseñanza está unida a la Orientación Traducción TécnicoCientífica de la carrera de grado del Traductorado de la Facultad de Lenguas, Universidad Nacional del Comahue (sede General Roca, Río Negro, Argentina). El presente trabajo presenta y describe una propuesta didáctica para la traducción de textos técnicos que sea adecuada a la formación de traductores y a las necesidades del medio. En la Facultad de Lenguas, la carrera de grado del Traductorado Público en idioma inglés fue creada en 1991 y desde esa fecha hasta la actualidad se han realizado dos cambios en el plan de estudios. Un estudio diacrónico realizado por Chaia (2014) pone de manifiesto un cambio de orientación de la carrera, en los dos últimos planes, desde un enfoque lingüístico a una orientación traductológica interdisciplinar. El plan de estudios 0503/96 considera a la traducción como una actividad netamente lingüística. Esto se evidencia en la carga horaria de las materias: Sintaxis, 
Semántica y Análisis del Discurso, Análisis Contrastivo y Elementos de Gramática Inglesa. Asimismo en el último cambio del plan de estudios (Plan 599/11) se expresa en la fundamentación la necesidad de introducir modificaciones relacionadas con los requerimientos del medio en el que se insertan los nuevos profesionales (Chaia 2014). Es decir que en el nuevo plan de estudios, a diferencia del anterior, se incluye un mayor porcentaje de materias específicas de Traducción que se detallan más adelante.

En la materia Traducción Técnica, que se encuentra en el $4^{\circ}$ año del nuevo plan de estudios (Plan 599/11) hemos observado que los alumnos, a diferencia de aquellos que cursaban el plan anterior, tenían un mayor conocimiento de aspectos teóricos relacionados con la adquisición de la competencia traductora, la identificación de los problemas y dificultades de traducción y el análisis y búsqueda de estrategias para cumplir con el encargo de traducción. Es importante destacar que en el nuevo plan se incluyen materias como Introducción a la Traducción, Traductología, Terminología y Documentación, Taller de Herramientas para la Traducción y Lengua aplicada a la Traducción. Todas estas materias proporcionan al alumno un bagaje de conocimientos que le permiten realizar el proceso de traducción desde un enfoque diferente al que hasta el momento primaba, que era de corte lingüístico. Es en este punto que se considera necesario implementar cambios en la metodología de enseñanza que hasta el momento se realizaba de manera transmisionista, es decir, era el docente el encargado de impartir los conocimientos y el futuro traductor un mero receptor de la información proporcionada por el docente. Al aplicar esta modalidad, el docente diseñaba la clase con ejercicios de traducción que los alumnos debían traducir de manera individual unos fragmentos de textos descontextualizados y solo se centraba en la búsqueda terminológica en diccionarios bilingües. Al momento de la corrección primaba aquella opción que el docente daba como la mejor versión. En muchos casos, sin tener en cuenta las estrategias que los alumnos habían implementado para obtener la traducción del fragmento, considerando de esta manera a la práctica de traducción fundamentalmente como una mera búsqueda del equivalente lingüístico. Es claro que esta metodología no resultaría adecuada para el nuevo grupo de alumnos, ya que en las materias anteriores han adquirido nociones teóricas sobre el proceso traductor. Es así que se plantea el problema de cómo abordar la traducción de los textos técnicos y adquirir la competencia traductora a través de una metodología de trabajo diferente.

Como el objetivo de nuestro nuevo plan de estudios es formar traductores competentes que puedan insertarse de manera rápida en el mercado laboral de la traducción es que se diseña una nueva metodología de trabajo en la materia Traducción Técnica que permita que los futuros traductores adquirieran las estrategias necesarias para desarrollar cada encargo de traducción. Las actividades que realizarán los alumnos están diseñadas en bloques. Cada bloque estará compuesto por tareas donde el trabajo se llevará a cabo de manera colaborativa y no individual. Las propuestas se irán complejizando de manera gradual con el fin de integrar la parte teórica con la práctica.

\section{MARCO TEÓRICO}

Para la elaboración de la metodología que aquí se presenta se ha recurrido a diferentes teorías traductológicas que comparten la concepción de la traducción como actividad comunicativa. Esta consideración es lo que funciona como el hilo conductor de la propuesta, ya que permite unificar e 
integrar las teorías de traducción y sus respectivos enfoques sobre la actividad traductora. En términos generales, la traducción es un acto de comunicación intercultural donde se deben considerar no solo los elementos de la comunicación intracultural (emisor, mensaje, tema, receptor, canal, medio) sino también los elementos de la comunicación intercultural liniciador del encargo, el traductor, la propia traducción y el receptor de la traducción) (Nord 1991; Kiraly 2000, p. 52). Desde una perspectiva comunicativa es fundamental tener en cuenta los factores que determinan la producción del texto de partida (TP) y del texto meta (TM). Es decir, aquellos factores que intervienen en la situación comunicativa original y meta. Desde la perspectiva comunicativa funcional resulta relevante la función que se le asigna a la traducción por el iniciador del encargo (Nord 1991). Para el enfoque textual además se debe considerar la dimensión pragmática y la dimensión semiótica (Hatim \& Mason, 1995). Por su parte, el enfoque cognitivo se interesa por los aspectos cognitivos de la traducción, las estrategias, los problemas y las fases del proceso de traducción: comprensión, desverbalización y reexpresión (Hurtado Albir, 2008, pp. 314-359). Cada uno de los enfoques presentados podrá resultar de gran utilidad, según el tipo de actividad que se desarrolle con los estudiantes, teniendo en cuenta el encargo de traducción, el tipo de texto, el género, la función del TP y el TM, el receptor, entre otros. La didáctica de traducción tiene como principal objetivo el estudio del proceso de formación de traductores e intérpretes, desarrollando y mejorando la competencia traductora. En esta propuesta didáctica el principal objetivo es que los alumnos adquieran la competencia traductora. Lo que se pretende es que el futuro traductor sea capaz de desarrollar, durante su proceso de formación, las habilidades y destrezas que son propias de un traductor profesional para lograr una traducción de calidad (Lobato Patricio, 2013). Es decir, saber hacer una traducción (Hurtado Albir, 2008) Este saber hacer se activa en una situación concreta y según las necesidades del momento (Galán Mañas, 2016).La competencia traductora tal como la describe el grupo PACTE (2003) constituye el sistema de conocimientos de tipo experto, necesario para traducir, conformado por conocimientos básicamente operativos y declarativos que permiten reflexionar ante cada decisión que se toma durante el proceso traductor. Este sistema está constituido por diferentes componentes interrelacionados denominados subcompetencias: la subcompetencia comunicativa en las dos lenguas, la subcompetencia extralingüística, la subcompetencia profesional, la subcompetencia psicofisiológica, la subcompetencia de transferencia en la que confluyen las anteriores, y la subcompetencia estratégica que interrelaciona a las demás (Hurtado Albir, 2008). En resumen, todas las subcompetencias funcionan de manera conjunta para constituir la competencia traductora y se integran en todo acto de traducción (PACTE, 2003).

Por su parte, Kelly $(2002,2005)$ propone un modelo de competencia traductora con el objetivo de proporcionar las bases para el diseño de un modelo curricular y la planificación de contenidos y metodología en el marco de la formación universitaria. La autora define a la competencia traductora como la macrocompetencia, que es el conjunto de habilidades, destrezas, conocimientos y actitudes que intervienen en la traducción como actividad experta. Las subcompetencias que integran esta clasificación son: subcompetencia comunicativa y textual en al menos dos lenguas y culturas, subcompetencia cultural, subcompetencia temática, subcompetencia instrumental profesional, subcompetencia psicofisiológica, subcompetencia interpersonal y subcompetencia estratégica. Todas las subcompetencias se relacionan entre sí, aunque es la subcompetencia estratégica la que integra a todas las demás durante el proceso de traducción. 
Las clasificaciones de competencia traductora, propuestas por ambas autoras, se tendrán en cuenta para desarrollar la metodología de trabajo que aquí se plantea para abordar la traducción de textos técnicos.

Como el principal objetivo de la propuesta es integrar los enfoques teóricos en la práctica de traducción, es que se considera la perspectiva socioconstructivista como eje fundamental de la metodología de trabajo. Las actividades que se diseñan integran los distintos enfoques con el fin de aplicar aspectos teóricos en la práctica de traducción que sea lo más cercana a la realidad profesional posible. Dentro del ámbito del socioconstructivismo, el proceso de enseñanza y aprendizaje es un proceso de construcción conjunta de significados entre estudiante y docente por medio de sus interacciones en relación con una actividad determinada (Coll, Colomina, Onrubia \& Rochera, 1995). Es la instancia de trabajo colaborativo (Kiraly 2000) donde el estudiante cumple el rol de participante activo y reflexivo en su propio proceso de aprendizaje, donde las experiencias y los conocimientos se construyen de manera conjunta, y el docente actúa como mediador, facilitador y guía al mismo tiempo que favorece la autonomía de trabajo de los integrantes del grupo. Es decir, mediante esta modalidad de trabajo cada participante contribuye desde su lugar a la solución de un problema planteado obteniendo así una visión más amplia de la realidad (Kiraly 2000).

Kiraly (2000) introduce el concepto de workshop como una forma de crear un ambiente de trabajo donde se interactúa, se toman decisiones, se evalúa y se construye activamente el conocimiento, no de manera individual, sino colaborativa. Es claro que en esta metodología el docente cumple el rol de facilitador del aprendizaje y el estudiante tiene la posibilidad de adquirir la competencia traductora a través de una situación lo más similar posible a la real. Al incorporar la metodología de taller en el proceso de enseñanza de la traducción especializada facilita la inversión de roles entre los actores (docente y alumnos) generando situaciones de debate permanentes donde se puede abordar el encargo de traducción desde una perspectiva diferente. Trabajar con material auténtico y en proyectos reales de traducción proporciona al alumno la posibilidad de incorporar los contenidos adquiridos en otras materias y, a la vez, construir su propio aprendizaje. Es por esta razón que se considera que traducir textos técnicos reales, en la etapa de formación, es relevante no solo para el desarrollo de la competencia traductora sino también para la competencia profesional. Además, trabajar con material auténtico y en proyectos similares al ámbito profesional fortalece vínculos entre la teoría y la práctica y promueve, en los futuros traductores, la creatividad, autonomía, responsabilidad, cooperación, y el espíritu crítico (Pacheco Aguilar, 2016).

Una vez definido el marco teórico general, se presentan las características de la Traducción Técnica, que es el ámbito donde se aplicarán los diferentes enfoques para lograr que los futuros traductores desarrollen la competencia traductora. La Traducción Técnica se clasifica dentro de la traducción especializada por abordar textos que se caracterizan por contar con una temática específica, usuarios particulares y situaciones comunicativas de tipo formal (Hurtado Albir, 2008). El objetivo de los técnicos es, por lo general, ayudar al lector a realizar una tarea (Byrne, 2012, p. 28). Es así que la información que se transmite debe ser de manera clara y efectiva. Por lo tanto, el lenguaje técnico busca la precisión en el contenido, la objetividad y la impersonalidad. El desafío de todo traductor técnico es asegurarse de que en la traducción esté presente toda la información importante y que 
siga las convenciones del género de manera tal que el receptor de esa información pueda usarla de manera precisa y efectiva (Byrne, 2006, p. 10). El propósito de la traducción técnica es presentar una nueva información técnica a un nuevo receptor, no reproducir el texto original en sí (Byrne, 2006, p. 11). Con el fin de cumplir con ese objetivo de la traducción técnica es que se desarrollan un conjunto de actividades para permitir que los futuros traductores adquieran la competencia traductora en este campo de la traducción especializada.

\section{PROPUESTA METODOLÓGICA}

La materia Traducción Técnica se encuentra en el $4^{\circ}$ año de la carrera de grado y el cursado es anual. El promedio de alumnos que cursan la materia cada año no supera la cantidad de 20.

Para llevar adelante la propuesta didáctica se delimitan los siguientes objetivos generales y específicos:

\section{Objetivos Generales}

- Brindaralosalumnoslasherramientasteórico-prácticas para desarrollarlassubcompetencias que forman parte de la competencia traductora.

- Conocer los aspectos profesionales y el mercado laboral de la traducción técnica.

- Proporcionar herramientas para efectivizar la documentación.

- Asimilar los principios metodológicos básicos.

- Saber detectar y resolver los problemas de traducción técnica.

\section{Objetivos Específicos}

Que el alumno logre:

- Identificar y analizar el encargo de traducción.

- Captar la finalidad comunicativa del encargo.

- Captar la importancia del destinatario de la traducción.

- Asumir la importancia de la etapa de comprensión del texto original (TO) para captar el sentido de los textos.

- Desarrollar estrategias para identificar los posibles problemas que puedan surgir durante el proceso de traducción.

- Conocer las fuentes básicas de documentación.

- Evaluar las fuentes de documentación.

- Adquirir estrategias de documentación.

- Adquirir estrategias para reformular la información del TO de manera apropiada.

- Conocer las diferentes técnicas de traducción que le permitan resolver los problemas que surjan en el proceso de traducción.

- Dominar las convenciones de escritura y las diferencias estilísticas en cada lengua.

- Desarrollar el espíritu crítico.

Con el fin de cumplir con los objetivos propuestos se desarrollan actividades que integren los aspectos teóricos en la práctica de traducción. Las actividades que se proponen están organizadas por bloques bimestrales. Cada bloque estará compuesto por actividades diseñadas para que los estudiantes 
desarrollen de manera gradual la competencia traductora. Las diferentes unidades didácticas que se abordarán en la materia se encuentran dentro del marco metodológico del enfoque por tareas propuesto por Hurtado Albir (1999, pp. 46-58) ya que implica una manera de integrar todos los elementos del proceso educativo: grupo de alumnos, docentes, objetivos, materiales para traducir y evaluación. En la evaluación por competencias deben participar todos los actores: docentes, alumnos (autoevaluación) y los compañeros entre sí (coevaluación). (Galán Mañas, 2016). La evaluación es permanente en los distintos bloques.

\section{Bloque 1}

El primer bloque se divide en dos fases. La primera, que tendrá una duración aproximada de cuatro encuentros de dos horas cada uno, tiene como objetivo caracterizar la traducción técnica. Para ello se trabajará con los conocimientos previos de los alumnos y se irán profundizando con lecturas complementarias donde los alumnos deberán trabajar de manera grupal para:

a) elaborar textos en la plataforma PEDCO (Plataforma de Educación a Distancia del Comahue) por ejemplo: una wiki.

b) diseñar un glosario con los diferentes conceptos con los que vamos a trabajar a lo largo del ciclo lectivo. Por ejemplo: definición de problemas, técnicas, estrategias, encargo de traducción, trabajo por proyecto, competencia traductora, género textual, entre otros.

c) debatir sobre los temas que se plantean en las diferentes lecturas complementarias.

El objetivo de la primera fase es retomar los conceptos abordados en las materias correlativas de años anteriores y aproximar al grupo de alumnos al ámbito de la traducción técnica para que, a partir de las diferentes actividades realizadas puedan caracterizar la traducción técnica.

En esta primera etapa se intenta que los alumnos, a través de la lectura de material teórico, comiencen a integrar aquellos aspectos teóricos que consideran a la traducción como una función comunicativa con los objetivos de la traducción técnica en particular.

La segunda fase consiste en un estudio exploratorio de las diferentes agencias de traducción, sugeridas por la cátedra, donde los alumnos deben registrar los diferentes géneros textuales que mencionan las agencias dentro del campo de la traducción técnica. Los alumnos pueden proponer otras agencias además de las sugeridas por la cátedra.

Una vez finalizado el estudio, los alumnos clasifican los diferentes géneros textuales teniendo en cuenta la bibliografía consultada en la fase 1.

Los futuros traductores clasifican los distintos géneros textuales que forman parte del ámbito técnico: instrucciones, patentes, fichas técnicas, manuales técnicos (Olahan 2016).

\section{Bloque 2}

En este bloque se realiza una selección de textos que pertenezcan a un mismo género que respondan al interés de los alumnos a partir de las actividades realizadas en la fase 2 del bloque 1. En esta primera etapa que es de aproximación a la traducción de un género técnico se seleccionan textos instructivos 
como manuales de instrucciones de electrodomésticos. Los encuentros estipulados para este bloque serán ocho de dos horas cada uno.

La selección de los textos se realiza, por un lado, según los criterios propuestos por Orozco (2003):

1) adecuación del texto (longitud, estructura interna, género, tipo, modo, campo y tono) al objetivo que persigue la unidad didáctica;

2) cantidad de problemas y el nivel de dificultad que presenta el texto en una o más fases del proceso de traducción (comprensión, transferencia, reformulación).

Por otro lado, Sevilla Muñoz (2006, p. 298) propone:

1) que los textos sean auténticos

2) que sean textos completos o contengan una idea completa

3) que sean textos variados en cuanto a temática, género y grado de especialización

4) que sean susceptibles de ser traducidos por los alumnos.

Para comenzar a identificar las características del género es importante que los alumnos realicen un análisis contrastivo del género que fue seleccionado para trabajar en este bloque. En esta etapa se utilizan textos paralelos en ambas lenguas y se comparten los resultados del análisis contrastivo. Para llevar a cabo esta parte de la actividad será de gran relevancia el aporte del enfoque textual para determinar la estructura del género por analizar: propósito retórico, propósito de la traducción y los patrones globales de los textos en cada lengua (Hatim \& Mason, 1995). Además integran esta propuesta de análisis con el enfoque funcionalista más precisamente con el análisis textual propuesto por Nord (1991).

Los alumnos trabajan en grupos con un encargo de traducción de un nivel de especialización adecuado:

1) Analizar el encargo de traducción teniendo en cuenta tanto la situación comunicativa del TP como la situación comunicativa del TM.

2) Analizar el texto de partida teniendo en cuenta los factores extratextuales e intratextuales propuestos por Nord (1991).

3) Identificar los posibles problemas y dificultades que puedan surgir durante el proceso de traducción.

4) Realizar la documentación que consideren pertinente para cumplir con el encargo de traducción.

5) Elaborar una versión de la traducción y trabajar sobre la misma hasta lograr una traducción adecuada al encargo de traducción.

6) Una primera instancia de corrección será entre los grupos.

7) Presentar la versión final para su evaluación.

La evaluación en este bloque es permanente y el docente es el facilitador del aprendizaje de los alumnos que comienzan a trabajar con encargos de traducción sencillos que a medida que se avance a los siguientes bloques se irán complejizando. En esta instancia el docente guía a los estudiantes a través del análisis textual y los diferentes pasos que conforman la actividad traductora a identificar 
y solucionar los posibles problemas que surjan durante la fase de comprensión del texto o en la de reexpresión. No implica que el docente anticipe las soluciones sino que guíe para que sean los propios alumnos los que resuelvan las dificultades.

\section{Bloque 3}

En este bloque los alumnos conformarán grupos donde el docente les asignará diferentes roles (corrector, editor, traductor) para realizar una traducción determinada. Los textos con los que van a trabajar presentan un grado de dificultad intermedio; es decir, en esta instancia los alumnos deberán resolver varios problemas que se presenten en el proceso. A cada grupo se le asigna el mismo texto, pero se trabaja con cuatro encargos diferentes.

Para cumplir con este encargo de traducción, los alumnos deben hacer uso de las herramientas que trabajaron en el Taller de Herramientas para la Traducción herramientas de gestión terminológica, herramientas de memorias de traducción de revisión ortográfica y estilística de control de calidad y de maquetación.

Al finalizar el proceso de traducción cada grupo deberá compartir con los demás grupos el encargo de traducción asignado y describir el trabajo que realizó cada integrante del grupo, los diferentes problemas, las estrategias que emplearon para resolver las dificultades y las conclusiones a las que arribaron.

\section{Bloque 4}

En el último bloque se trabaja con una metodología que comprende a las demás actividades que se presentaron en los bloques anteriores. La metodología que se emplea en esta instancia es el trabajo colaborativo por proyecto. Esta técnica de trabajo en el aula prepara al futuro profesional para el mundo laboral, ya que se trata de simular las situaciones reales del traductor profesional (Lobato Patricio, 2013).

El docente presenta a los alumnos un encargo real de traducción. El texto para traducir será seleccionado de acuerdo con los criterios expuestos en el bloque 2. En este caso se presenta un texto instructivo de un nivel de especialización más elevado: manual de instrucciones para aplicar una cinta de kinesiología. La traducción es solicitada por un equipo de kinesiólogos de una institución pública local. Una vez presentado el encargo de traducción los alumnos conforman los grupos de trabajo. Cada integrante del grupo elige su rol (traductor, corrector, editor). Para la elaboración del texto meta la consulta al cliente es constante. El rol del docente es de guía permanente en este proceso de trabajo. Este tipo de tarea que se ofrece a los futuros traductores fortalece el trabajo autónomo y el espíritu crítico.

El docente designa los fragmentos del texto que cada grupo tiene que traducir. Cada grupo se organiza para trabajar y debe respetar el cronograma de entrega parcial del trabajo para que el docente revise la traducción. En esta parte del trabajo se espera que los alumnos puedan aplicar los conocimientos presentados en los bloques anteriores y transferirlos en el proyecto de traducción propuesto. La traducción se realizará usando un software libre de memoria de traducción. Uno de los grupos es el encargado de recopilar toda la traducción y realizar el proceso de revisión y edición para presentar la versión final al equipo de cátedra en el tiempo estipulado. 
De esta manera, los alumnos trabajan de manera autónoma integrando los conocimientos que trabajaron en bloques anteriores.

Una vez finalizado el trabajo colaborativo por proyecto se imparte a cada alumno una breve encuesta donde deben plasmar sus impresiones sobre el trabajo realizado en este bloque. Los resultados obtenidos de las respuestas de los alumnos muestran qué trabajos de este tipo los motiva para su desarrollo como futuros profesionales. El equipo docente observa, a partir de la implementación de las actividades integrando diferentes enfoques teóricos a la parte práctica de la traducción, cómo los futuros traductores adquieren de manera gradual la competencia traductora que es principal objetivo por cumplir durante el dictado de la materia.

\section{CONCLUSIÓN}

Las actividades diseñadas dentro de esta metodología pretenden aportar al alumno las herramientas para desarrollar la competencia traductora. Entre las características más innovadoras de la metodología elaborada figuran: la incorporación del Taller como forma de trabajo, el uso de herramientas aplicadas a la traducción que ayudan en el proceso, la elaboración de un modelo de análisis textual de fácil manejo y con indicaciones claras sobre los pasos para recorrer el proceso traductor, la integración de teorías traductológicas diferentes que comparten una concepción común de la traducción como comunicación intercultural, y la aplicación de un enfoque didáctico colaborativo en un contexto tradicionalmente acostumbrado a metodologías transmisionistas.

A partir de la implementación de las diferentes actividades propuestas en cada bloque se observó que los alumnos fueron desarrollando de manera progresiva, sistemática y autónoma la competencia traductora en el ámbito de la traducción técnica. En conclusión, la metodología que he presentado en este artículo representa un aporte dentro del ámbito de la didáctica de la traducción y se espera que los nuevos planes de estudios promuevan la implementación de diferentes metodologías de enseñanza de la traducción en la etapa de formación. 


\section{REFERENCIAS}

Byrne, J. (2006). Technical Translation Usability Strategies for Translating Technical Documentation. Dordrecht: Springer.

Byrne, J. (2012). Scientific and technical translation explained. Manchester: St. Jerome Publishing.

Chaia, M. C. G. lagosto 2014). La carrera de Traductor de la Universidad Nacional del Comahue: desde un enfoque lingüístico hacia una orientación traductológica interdisciplinaria. Trabajo presentado en el II Ateneo interuniversitario de Traductología "La formación para la traducción”. Facultad de Humanidades y Ciencias de la Educación de la Universidad Nacional de la Plata, Argentina.

Coll, C., Colomina, R., Onrubia, J. \& Rochera, M. J. (1995). Actividad conjunta y habla: una aproximación al estudio de los mecanismos de influencia educativa. En P. Fernández Berrocal \& M. A. Melero (Eds). La interacción social en contextos educativos (pp. 189-232). Madrid: Siglo XXI.

Galán Mañas, I. (2016). La Formación de Traductores Científico-Técnicos. ¿Qué y Cuándo se Enseña y Qué y Cuándo se evalúa? Mapeo de las Competencias. En L. Molina \& L. Santamaría (Eds.), Traducción, interpretación y estudios interculturales (pp. 69-88). Granada: Editorial Comares.

Hatim, B. \& Mason, I. (1995). Teoría de la Traducción. Una aproximación al discurso. Barcelona: Ariel.

Hurtado Albir, A. (1999). Enseñar a traducir. Metodología en la formación de traductores e intérpretes. Madrid: Edelsa.

Hurtado Albir, A. (2008). Traducción y Traductología. Introducción a la Traductología. Madrid: Cátedra.

Kelly, D. (2002). Un modelo de competencia traductora: bases para el diseño curricular. Puentes, 1, 9-20.

Kelly, D. (2005). A Handbook for Translator Trainers. Translation Practices Explained. Manchester: St. Jerome.

Kiraly, D. (2000). A Social Constructivist Approach to Translator Education. Manchester: St. Jerome Publishing.

Lobato Patricio, J. (2013). Propuesta Didáctica para las clases de Traducción especializada: el Aprendizaje Basado en Proyectos. Revista de Estudios Filológicos, 25. Recuperado de https://goo.gl/ZZLtha

Nord, C. (1991). Text Analysis in Translation. Theory, Methodology, and Didactic Application of a Model for Translation-Oriented Text Analysis. Amsterdan: Atlanta.

Olahan, M. (2016). Scientific and Technical Translation. New York, NY: Routledge.

Orozco, M. (20 de noviembre 2003). La selección de textos para la enseñanza de la traducción general o iniciación a la traducción (II), El Trujamán. Recuperado de https://goo.gl/UpxgBL

Pacheco Aguilar, R. (2016). Chapter 1: The Question of Authenticity in Translation Education from the Perspective of Educational Philosophy. En D. Kiraly (Ed.), Towards Authentic Experiential Learning in Translator Education (pp. 13-32). Göttingen: V\&R unipress.

PACTE (2003). Building a Translation competence model. En F. Alves (Ed.), Triangulating Translation: Perspectives in process oriented research (pp. 46-66). Amsterdam: John Benjamins.

Sevilla Muñoz, M. (2006). Análisis del potencial pedagógico de un texto como material didáctico en la asignatura de traducción científico-técnica. Didáctica. Lengua y Literatura, 18, 295-314.

(c) Los autores. Este artículo es publicado por la Revista Digital de Investigación en Docencia Universitaria del Área de Institutional Research and Effectiveness de la Dirección de Aseguramiento de la Calidad, Universidad Peruana de Ciencias Aplicadas. Este es un artículo de acceso abierto, distribuido bajo los términos de la LicenciaCreativeCommons Atribución-Compartirlgual 4.0 Internacional.I http://creativecommons.org/licenses/bysa/4.0/I, que permite el uso no comercial, distribución y reproducción en cualquier medio, siempre que la obra original sea debidamente citada. 